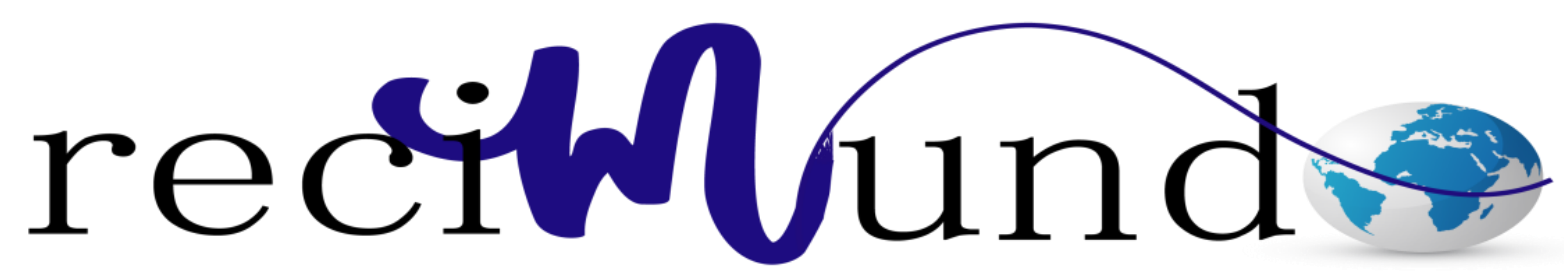

Revista Científica Mundo de la Investigación y el Conocimiento

Andrea Carolina Mariño Jara ${ }^{\text {a }}$; Mary Isabel Vinces Zambrano ${ }^{\text {b; }}$ Andrea Natacha

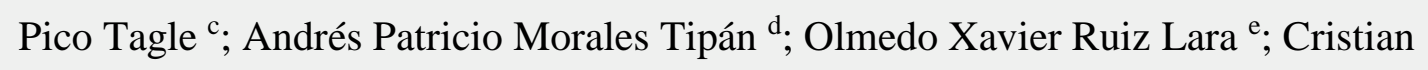
Manuel Chango Checa ${ }^{\mathrm{f}}$

Factores de riesgo que inciden en la presencia de diabetes

Risk factors that affect the presence of diabetes

Revista Científica Mundo de la Investigación y el Conocimiento. Vol. 2 núm.4, Octubre, ISSN: 2588-073X, 2018, pp. 189-238

DOI: 10.26820/recimundo/2.(4).octubre.2018.189-238

URL: http://www.recimundo.com/index.php/es/article/view/351

Editorial Saberes del Conocimiento

Recibido: 15/07/2018 Aceptado: 05/08/2018 Publicado: 30/11/2018

Correspondencia: director@ recimundo.com
a. Médico Residente; Hospital General Provincial Latacunga
b. Médico Residente; Hospital General Manta
c. Médico Residente; Hospital General Manta
d. Médico Residente Traumatología; Hospital IESS Ibarra
e. Médico Residente de Traumatología; Hospital General Ibarra
f. Residente Asistencial de Anestesiología; Hospital Pablo Arturo Suárez 


\section{Factores de riesgo que inciden en la presencia de diabetes}

Vol. 2, núm. 4., (2018)

Andrea Carolina Mariño Jara; Mary Isabel Vinces Zambrano; Andrea Natacha Pico Tagle;

Andrés Patricio Morales Tipán; Olmedo Xavier Ruiz Lara; Cristian Manuel Chango Checa

\section{RESUMEN}

Una gran cantidad de personas ignoran cuan graves pueden ser las consecuencias de la diabetes, directamente en la salud y en la calidad de vida. Tener la glucosa en sangre fuera de los parámetros normales puede ocasionar serios daños en disímiles órganos del cuerpo, como los vasos sanguíneos, riñones, corazón y ojos. Vale destacar que los daños ocasionados en los vasos sanguíneos pueden provocar un derrame cerebral o hasta un ataque en el corazón. La diabetes es una enfermedad que se presenta cuando el nivel de glucosa en la sangre, también conocido como azúcar en la sangre, es demasiado alto. La glucosa en la sangre es la principal fuente de energía y proviene de los alimentos. La insulina, una hormona que produce el páncreas, ayuda a que la glucosa de los alimentos ingrese en las células para usarse como energía. Con el tiempo, el exceso de glucosa en la sangre puede causar problemas de salud. Aunque la diabetes no tiene cura, la persona con diabetes puede tomar medidas para controlar su enfermedad y mantenerse sana.

Palabras claves: Diabetes; calidad de vida; insulina; nivel de glucosa; energía; corazón. 


\title{
Factores de riesgo que inciden en la presencia de diabetes
}

Vol. 2, núm. 4., (2018)

Andrea Carolina Mariño Jara; Mary Isabel Vinces Zambrano; Andrea Natacha Pico Tagle; Andrés Patricio Morales Tipán; Olmedo Xavier Ruiz Lara; Cristian Manuel Chango Checa

\begin{abstract}
A lot of people are unaware how serious the consequences of diabetes, directly on the health and quality of life can be. You have glucose in blood outside the normal parameters can cause serious damage in different organs of the body, such as blood vessels, kidneys, heart and eyes. It is worth noting that damage in the blood vessels can cause a stroke or even a heart attack. Diabetes is a disease that occurs when the level of glucose in the blood, also known as blood sugar, is too high. Blood glucose is the main source of energy and comes from food. Insulin, a hormone produced by the pancreas, helps glucose from food to enter in cells for use as energy. Eventually, the excess of glucose in the blood it can cause health problems. Although diabetes has no cure, the person with diabetes can take steps to control their disease and stay healthy.
\end{abstract}

Keywords: Diabetes; quality of life; insulin; glucose; energy and heart level. 


\section{Factores de riesgo que inciden en la presencia de diabetes}

Vol. 2, núm. 4., (2018)

Andrea Carolina Mariño Jara; Mary Isabel Vinces Zambrano; Andrea Natacha Pico Tagle;

Andrés Patricio Morales Tipán; Olmedo Xavier Ruiz Lara; Cristian Manuel Chango Checa

\section{Introducción.}

La diabetes es una enfermedad en la que los niveles de glucosa (azúcar) de la sangre están muy altos. La glucosa proviene de los alimentos que consume. La insulina es una hormona que ayuda a que la glucosa entre a las células para suministrarles energía. En la diabetes tipo 1, el cuerpo no produce insulina. En la diabetes tipo 2, la más común, el cuerpo no produce o no usa la insulina de manera adecuada. Sin suficiente insulina, la glucosa permanece en la sangre. (1)

Con el tiempo, el exceso de glucosa en la sangre puede causar problemas serios. Puede dañar los ojos, los riñones y los nervios. La diabetes también puede causar enfermedades cardíacas, derrames cerebrales y la necesidad de amputar un miembro. Las mujeres embarazadas también pueden desarrollar diabetes, llamada diabetes gestacional. (1)

Un análisis de sangre puede mostrar si tiene diabetes. Un tipo de prueba, la A1c, también puede comprobar cómo está manejando su diabetes. El ejercicio, el control de peso y respetar el plan de comidas puede ayudar a controlar la diabetes. También debe controlar el nivel de glucosa en sangre y, si tiene receta médica, tomar medicamentos. (2)

\section{¿Qué es la Diabetes?}

La diabetes es una enfermedad que se presenta cuando el nivel de glucosa en la sangre, también conocido como azúcar en la sangre, es demasiado alto. La glucosa en la sangre es la principal fuente de energía y proviene de los alimentos. La insulina, una hormona que produce el páncreas, ayuda a que la glucosa de los alimentos ingrese en las células para usarse como 


\section{Factores de riesgo que inciden en la presencia de diabetes}

Vol. 2, núm. 4., (2018)

Andrea Carolina Mariño Jara; Mary Isabel Vinces Zambrano; Andrea Natacha Pico Tagle; Andrés Patricio Morales Tipán; Olmedo Xavier Ruiz Lara; Cristian Manuel Chango Checa

energía. Algunas veces, el cuerpo no produce suficiente o no produce nada de insulina o no la usa adecuadamente y la glucosa se queda en la sangre y no llega a las células. (3)

Con el tiempo, el exceso de glucosa en la sangre puede causar problemas de salud. Aunque la diabetes no tiene cura, la persona con diabetes puede tomar medidas para controlar su enfermedad y mantenerse sana.

A veces las personas cuando tiene diabetes dicen que tienen "un poquito alto el azúcar" o que tienen "prediabetes". Estos términos nos hacen pensar que la persona realmente no tiene diabetes o que su caso es menos grave. Sin embargo, todos los casos de diabetes son graves.

\section{¿Cuáles son los diferentes tipos de diabetes? (4)}

Los principales tipos de diabetes son tipo 1, tipo 2 y la diabetes gestacional.

\section{Diabetes tipo 1}

Con la diabetes tipo 1, el cuerpo no produce insulina porque el sistema inmunitario ataca y destruye las células del páncreas que la producen. Por lo general, se diagnostica la diabetes tipo 1 en niños y adultos jóvenes, aunque puede aparecer a cualquier edad. Las personas con diabetes tipo 1 tienen que usar insulina todos los días para sobrevivir.

\section{Diabetes tipo 2}

Con la diabetes tipo 2, el cuerpo no produce o no usa la insulina adecuadamente. La diabetes tipo 2 puede aparecer a cualquier edad, incluso durante la infancia. Sin embargo, este 


\section{Factores de riesgo que inciden en la presencia de diabetes}

Vol. 2, núm. 4., (2018)

Andrea Carolina Mariño Jara; Mary Isabel Vinces Zambrano; Andrea Natacha Pico Tagle;

Andrés Patricio Morales Tipán; Olmedo Xavier Ruiz Lara; Cristian Manuel Chango Checa

tipo de diabetes se presenta con mayor frecuencia en las personas de mediana edad y en los ancianos. Este es el tipo más común de diabetes.

\section{Diabetes gestacional (5)}

La diabetes gestacional afecta a algunas mujeres durante el embarazo. La mayoría de las veces, este tipo de diabetes desaparece después de que nazca el bebé.

Sin embargo, cuando una mujer ha tenido diabetes gestacional, tiene más probabilidad de sufrir de diabetes tipo 2 más adelante en la vida. A veces, la diabetes que se diagnostica durante el embarazo es en realidad diabetes tipo 2.

\section{Otros tipos de diabetes}

Otros tipos menos comunes de esta enfermedad incluyen la diabetes monogénica, que es una forma hereditaria de diabetes y la diabetes relacionada con la fibrosis quística.

\section{¿Qué tan frecuente es la diabetes?}

Para el año 2015, 30.3 millones de personas en los Estados Unidos, es decir, el 9.4 por ciento de la población, tenían diabetes. Más de 1 de cada 4 de estas personas no sabían que tenían la enfermedad. La diabetes afecta a 1 de cada 4 personas mayores de 65 años de edad. Alrededor del 90-95 por ciento de los casos en adultos corresponden a la diabetes tipo 2. (3)

\section{¿Quién tiene más probabilidad de sufrir de diabetes tipo 2?}




\section{Factores de riesgo que inciden en la presencia de diabetes}

Vol. 2, núm. 4., (2018)

Andrea Carolina Mariño Jara; Mary Isabel Vinces Zambrano; Andrea Natacha Pico Tagle; Andrés Patricio Morales Tipán; Olmedo Xavier Ruiz Lara; Cristian Manuel Chango Checa

Las personas que tienen más probabilidad de desarrollar diabetes tipo 2 son las que tienen más de 45 años de edad, antecedentes familiares de diabetes o sobrepeso. La inactividad física, la raza y ciertos problemas de salud, como la presión arterial alta, también afectan la probabilidad de tener diabetes tipo 2.

Además, la probabilidad de desarrollar diabetes tipo 2 es mayor si se tiene prediabetes o si se tuvo diabetes gestacional cuando estaba embarazada. Aprenda más sobre los factores de riesgo de la diabetes tipo 2.

\section{¿Qué problemas de salud pueden tener las personas con diabetes? (6)}

Con el tiempo, los niveles altos de glucosa en la sangre causan problemas como:

- $\quad$ enfermedades del corazón

- $\quad$ accidentes cerebrovasculares

- $\quad$ enfermedades de los riñones

- $\quad$ problemas de los ojos

- $\quad$ enfermedades dentales

- $\quad$ lesiones en los nervios

- $\quad$ problemas de los pies

Las personas pueden tomar algunas medidas para reducir la probabilidad de tener estos problemas de salud relacionados con la diabetes. 


\section{Factores de riesgo que inciden en la presencia de diabetes}

Vol. 2, núm. 4., (2018)

Andrea Carolina Mariño Jara; Mary Isabel Vinces Zambrano; Andrea Natacha Pico Tagle;

Andrés Patricio Morales Tipán; Olmedo Xavier Ruiz Lara; Cristian Manuel Chango Checa

\section{Síntomas y causas de la diabetes}

\section{¿Cuáles son los síntomas de la diabetes?}

Los síntomas de la diabetes incluyen:

- $\quad$ aumento de la sed y de las ganas de orinar

- $\quad$ aumento del apetito

- $\quad$ fatiga

- $\quad$ visión borrosa

- $\quad$ entumecimiento u hormigueo en las manos o los pies

- $\quad$ úlceras que no cicatrizan

- $\quad$ pérdida de peso sin razón aparente

Los síntomas de la diabetes tipo 1 pueden aparecer rápidamente, en cuestión de semanas. En cambio, los síntomas de la diabetes tipo 2 suelen progresar muy despacio, a lo largo de varios años, y pueden ser tan leves que a veces ni siquiera se notan. Muchas personas con diabetes tipo 2 no tienen síntomas.

Algunas solo se enteran de que tienen la enfermedad cuando surgen problemas de salud relacionados con la diabetes, como visión borrosa o problemas del corazón.

\section{¿Qué causa la diabetes tipo 1?}




\section{Factores de riesgo que inciden en la presencia de diabetes}

Vol. 2, núm. 4., (2018)

Andrea Carolina Mariño Jara; Mary Isabel Vinces Zambrano; Andrea Natacha Pico Tagle;

Andrés Patricio Morales Tipán; Olmedo Xavier Ruiz Lara; Cristian Manuel Chango Checa

La diabetes tipo 1 ocurre cuando el sistema inmunitario, que combate las infecciones, ataca y destruye las células beta del páncreas que son las que producen la insulina. Los científicos piensan que la diabetes tipo 1 es causada por genes y factores ambientales, como los virus, que pueden desencadenar la enfermedad. Algunos estudios como el TrialNet están enfocados en identificar las causas de la diabetes tipo 1 y las posibles maneras de prevenir o retrasar el progreso o comienzo de la enfermedad.

\section{¿Qué causa la diabetes tipo 2?}

La diabetes tipo 2, la forma más común de la enfermedad, es causada por varios factores, entre ellos, el estilo de vida y los genes.

\section{Sobrepeso, obesidad e inactividad física}

Una persona tiene mayor probabilidad de desarrollar diabetes tipo 2 si no se mantiene físicamente activa y tiene sobrepeso u obesidad. Algunas veces, el exceso de peso causa resistencia a la insulina y es frecuente en personas con diabetes tipo 2.

La ubicación de la grasa corporal también tiene importancia. El exceso de grasa en el vientre está vinculado con la resistencia a la insulina, la diabetes tipo 2 y las enfermedades del corazón y los vasos sanguíneos. Para ver si su peso representa un riesgo para la aparición de la diabetes tipo 2 .

\section{Resistencia a la insulina (7)}




\section{Factores de riesgo que inciden en la presencia de diabetes}

Vol. 2, núm. 4., (2018)

Andrea Carolina Mariño Jara; Mary Isabel Vinces Zambrano; Andrea Natacha Pico Tagle; Andrés Patricio Morales Tipán; Olmedo Xavier Ruiz Lara; Cristian Manuel Chango Checa

La diabetes tipo 2 suele comenzar con resistencia a la insulina, una afección en la que el músculo, el hígado y las células grasas no usan adecuadamente la insulina. Como resultado, el cuerpo necesita más insulina para que la glucosa pueda ingresar en las células. Al principio, el páncreas produce más insulina para cubrir el aumento de la demanda, pero con el tiempo deja de producir suficiente insulina y aumentan los niveles de glucosa en la sangre.

\section{Genes $y$ antecedentes familiares}

Igual que sucede con la diabetes tipo 1, ciertos genes pueden hacer que una persona sea más propensa a tener diabetes tipo 2. La enfermedad tiene una tendencia hereditaria y se presenta con mayor frecuencia en estos grupos raciales o étnicos:

- afroamericanos

- $\quad$ nativos de Alaska

- $\quad$ indígenas estadounidenses

- $\quad$ estadounidenses de origen asiático

- hispanos o latinos

- $\quad$ nativos de Hawái

- nativos de las Islas del Pacífico

Los genes también pueden aumentar el riesgo de diabetes tipo 2 al aumentar la tendencia de la persona al sobrepeso u obesidad. 


\section{Factores de riesgo que inciden en la presencia de diabetes}

Vol. 2, núm. 4., (2018)

Andrea Carolina Mariño Jara; Mary Isabel Vinces Zambrano; Andrea Natacha Pico Tagle;

Andrés Patricio Morales Tipán; Olmedo Xavier Ruiz Lara; Cristian Manuel Chango Checa

\section{¿Qué causa la diabetes gestacional?}

Los científicos creen que la diabetes gestacional, un tipo de diabetes que se presenta durante el embarazo, es causada por cambios hormonales, factores genéticos y factores del estilo de vida.

\section{Resistencia a la insulina}

Ciertas hormonas producidas por la placenta contribuyen a la resistencia a la insulina, que se presenta en todas las mujeres hacia el final del embarazo.

La mayoría de las mujeres embarazadas pueden producir suficiente insulina para superar la resistencia a la insulina, pero algunas no. La diabetes gestacional ocurre cuando el páncreas no produce suficiente insulina.

Igual que sucede con la diabetes tipo 2, el exceso de peso está vinculado a la diabetes gestacional. Las mujeres que tienen sobrepeso u obesidad tal vez ya tengan resistencia a la insulina cuando quedan embarazadas. El aumento excesivo de peso durante el embarazo también puede ser un factor. 


\section{Factores de riesgo que inciden en la presencia de diabetes}

Vol. 2, núm. 4., (2018)

Andrea Carolina Mariño Jara; Mary Isabel Vinces Zambrano; Andrea Natacha Pico Tagle;

Andrés Patricio Morales Tipán; Olmedo Xavier Ruiz Lara; Cristian Manuel Chango Checa

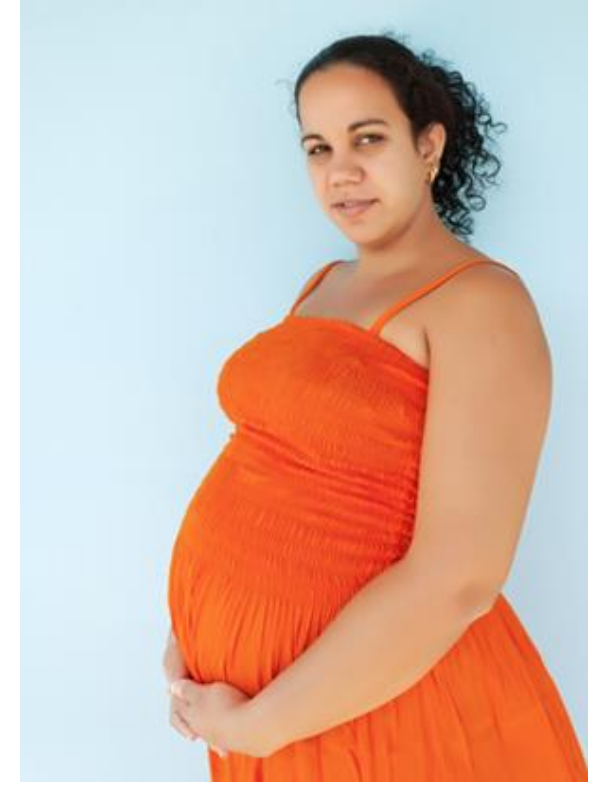

Los cambios hormonales, el aumento excesivo de peso y los antecedentes familiares pueden contribuir a la diabetes gestacional.

\section{Genes y antecedentes familiares}

Las mujeres con antecedentes familiares de diabetes tienen mayor probabilidad de desarrollar diabetes gestacional, lo cual sugiere que los genes desempeñan un papel. Los genes también pueden explicar por qué el trastorno se presenta con mayor frecuencia en las afroamericanas, las indígenas estadounidenses, las asiáticas y las hispanas o latinas.

\section{¿Qué más puede causar diabetes?}

Algunas mutaciones genéticas, otras enfermedades, la lesión del páncreas y ciertas medicinas también pueden causar diabetes.

\section{Mutaciones genéticas}




\section{Factores de riesgo que inciden en la presencia de diabetes}

Vol. 2, núm. 4., (2018)

Andrea Carolina Mariño Jara; Mary Isabel Vinces Zambrano; Andrea Natacha Pico Tagle; Andrés Patricio Morales Tipán; Olmedo Xavier Ruiz Lara; Cristian Manuel Chango Checa

- La diabetes monogénica es causada por mutaciones o cambios en un solo gen. Estos cambios suelen transmitirse entre miembros de la familia, pero a veces la mutación genética tiene lugar espontáneamente. La mayoría de estas mutaciones genéticas causan diabetes porque hacen que el páncreas pierda su capacidad de producir insulina.

- Los tipos más comunes de diabetes mono génica son la diabetes neonatal y la diabetes del adulto de inicio juvenil (MODY, por sus siglas en inglés). La diabetes neonatal se presenta en los primeros 6 meses de vida. Los médicos suelen diagnosticar la diabetes del adulto de inicio juvenil durante la adolescencia o la adultez temprana, pero a veces la enfermedad no se diagnostica sino hasta más adelante en la vida.

- La fibrosis quística produce un exceso de mucosidad espesa que causa cicatrización en el páncreas. Estas cicatrices pueden impedir que el páncreas produzca suficiente insulina.

- La hemocromatosis hace que el cuerpo almacene demasiado hierro. Si la enfermedad no se trata, el hierro puede acumularse en el páncreas y otros órganos y dañarlos.

\section{Enfermedades hormonales}

Algunas enfermedades hacen que el cuerpo produzca una cantidad excesiva de ciertas hormonas, lo cual algunas veces causa resistencia a la insulina y diabetes. 


\section{Factores de riesgo que inciden en la presencia de diabetes}

Vol. 2, núm. 4., (2018)

Andrea Carolina Mariño Jara; Mary Isabel Vinces Zambrano; Andrea Natacha Pico Tagle; Andrés Patricio Morales Tipán; Olmedo Xavier Ruiz Lara; Cristian Manuel Chango Checa

- $\quad$ El síndrome de Cushing se presenta cuando el cuerpo produce demasiado cortisol, que con frecuencia se conoce con el nombre de "hormona del estrés".

- La acromegalia se presenta cuando el cuerpo produce demasiada hormona del crecimiento.

- El hipertiroidismo se presenta cuando la glándula tiroides produce demasiada hormona tiroidea.

\section{Lesiones o extracción del páncreas}

La pancreatitis, el cáncer de páncreas y los traumatismos pueden dañar las células beta o hacer que pierdan parte de su capacidad de producir insulina, lo cual da lugar a la diabetes. Si se extirpa el páncreas lesionado, aparece la diabetes como resultado de la pérdida de las células beta.

\section{Medicinas}

Algunas veces, ciertas medicinas pueden dañar las células beta $o$ alterar el funcionamiento de la insulina.

Estos incluyen:

- $\quad$ niacina, un tipo de vitamina B3

- $\quad$ ciertos tipos de diuréticos

- $\quad$ medicinas anticonvulsivos 


\section{Factores de riesgo que inciden en la presencia de diabetes}

Vol. 2, núm. 4., (2018)

Andrea Carolina Mariño Jara; Mary Isabel Vinces Zambrano; Andrea Natacha Pico Tagle; Andrés Patricio Morales Tipán; Olmedo Xavier Ruiz Lara; Cristian Manuel Chango Checa

- $\quad$ medicinas psiquiátricos

- $\quad$ medicinas para tratar el virus de la inmunodeficiencia humana (VIH)

- $\quad$ pentamidina, una medicina que se usa para tratar un tipo de neumonía

- glucocorticoides, medicinas que se usan para tratar enfermedades inflamatorias como la artritis reumatoide, el asma, el lupus y la colitis ulcerativa

- $\quad$ medicinas anti-rechazo, que se usan para hacer que el cuerpo no rechace un órgano trasplantado

Las estatinas, que son medicinas para reducir los niveles de colesterol LDL (el "colesterol malo"), pueden aumentar ligeramente la probabilidad de diabetes. Sin embargo, las estatinas protegen contra las enfermedades del corazón y los accidentes cerebrovasculares. Por esta razón, los grandes beneficios de tomar estatinas superan la pequeña probabilidad de desarrollar diabetes.

Una gran cantidad de personas ignoran cuan graves pueden ser las consecuencias de la diabetes, directamente en la salud y en la calidad de vida. Tener la glucosa en sangre fuera de los parámetros normales puede ocasionar serios daños en disímiles órganos del cuerpo, como los vasos sanguíneos, riñones, corazón y ojos. Vale destacar que los daños ocasionados en los vasos sanguíneos pueden provocar un derrame cerebral o hasta un ataque en el corazón. 


\section{Factores de riesgo que inciden en la presencia de diabetes}

Vol. 2, núm. 4., (2018)

Andrea Carolina Mariño Jara; Mary Isabel Vinces Zambrano; Andrea Natacha Pico Tagle;

Andrés Patricio Morales Tipán; Olmedo Xavier Ruiz Lara; Cristian Manuel Chango Checa

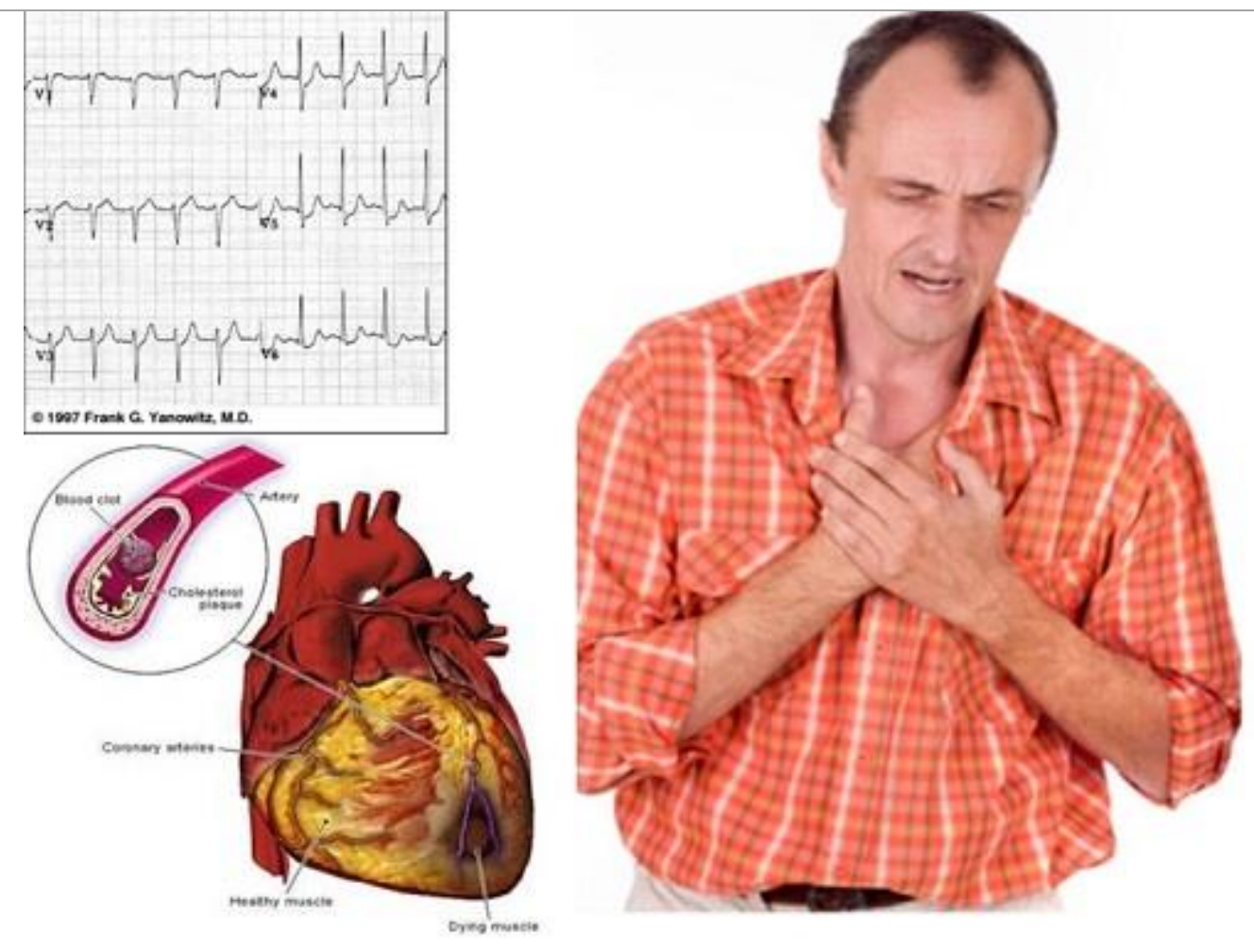

La diabetes puede ocasionar severos daños en el corazón del paciente

Siete de las consecuencias más comunes que puede provocar la diabetes.

1. Problemas visuales. Puede provocar glaucoma en la vista, lo que se traduce como una lesión del nervio óptico ocasionado por el aumento de la tensión ocular. En caso de que esta enfermedad se encuentre avanzada, el diabético corre el riesgo de quedar ciego, sin posibilidades de revertir el daño. También se debe mencionar la retinopatía diabética, la cual provoca derrames que deben ser tratados a tiempo, de otra manera pueden llegar a ocasionar hemorragias y otros problemas que pueden llevar al desprendimiento de la retina. Son muy comunes las cataratas en mayores diabéticos, pertenecientes a la tercera edad. 


\section{Factores de riesgo que inciden en la presencia de diabetes}

Vol. 2, núm. 4., (2018)

Andrea Carolina Mariño Jara; Mary Isabel Vinces Zambrano; Andrea Natacha Pico Tagle; Andrés Patricio Morales Tipán; Olmedo Xavier Ruiz Lara; Cristian Manuel Chango Checa

2. Pie diabético. Es una infección, ulceración o destrucción de los tejidos profundos relacionados con alteraciones neurológicas y distintos grados de enfermedad vascular periférica en las extremidades inferiores que afectan generalmente a los diabéticos. Para poder determinar si un paciente tiene pie diabético debe presentar los siguientes síntomas en las extremidades inferiores: alteraciones de los reflejos, dolor y reducción de la temperatura, heridas que no cicatrizan, sensación de hormigueo y/o sequedad de la piel.

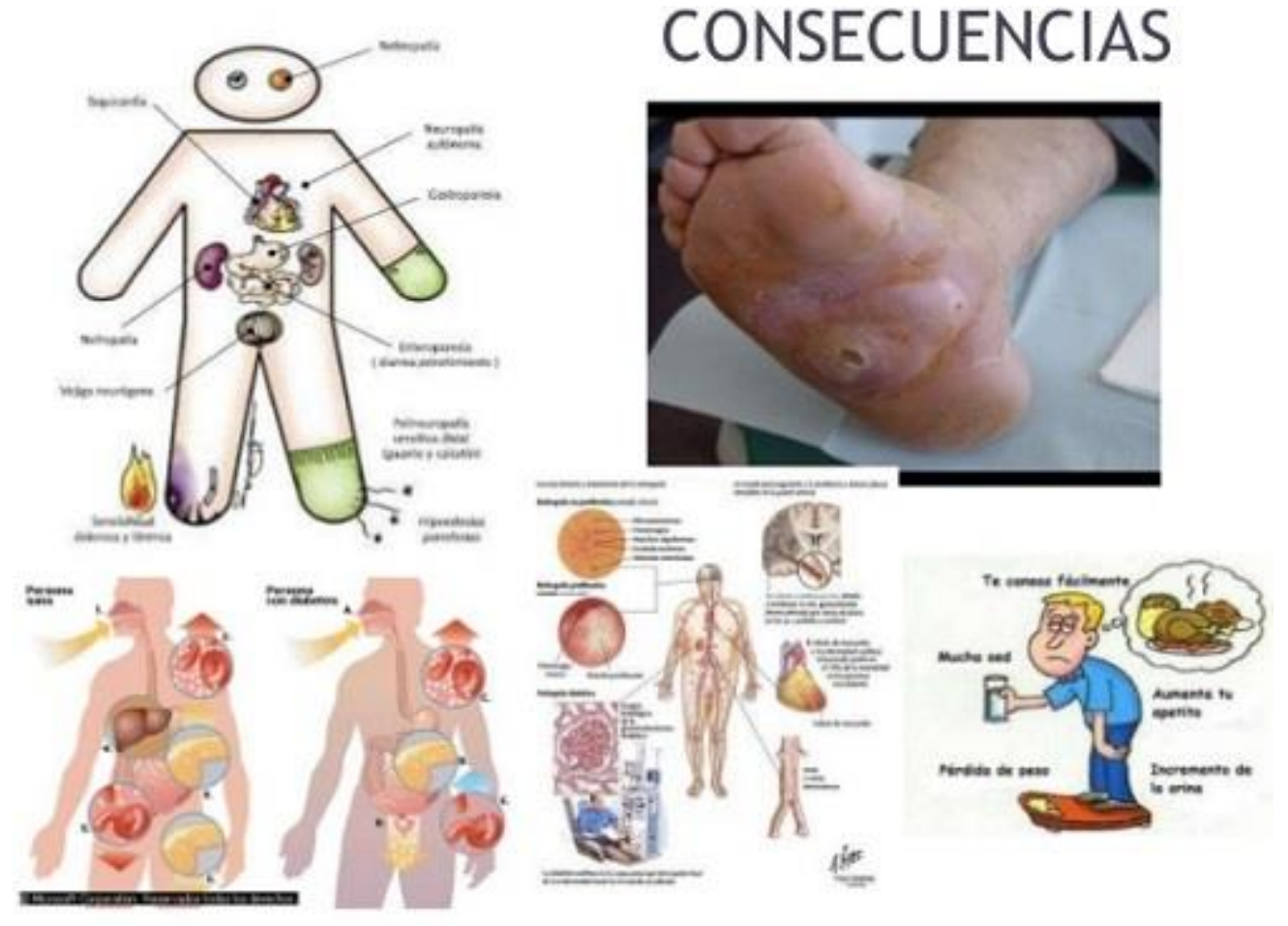

Sin el tratamiento debido, una úlcera del pie diabético puede significar la pérdida total o parcial de la extremidad afectada.

3. Enfermedad renal. El exceso de glucosa en sangre ocasiona toxicidad, problemas inflamatorios y degenerativos en los riñones. También provoca que los 


\section{Factores de riesgo que inciden en la presencia de diabetes}

Vol. 2, núm. 4., (2018)

Andrea Carolina Mariño Jara; Mary Isabel Vinces Zambrano; Andrea Natacha Pico Tagle;

Andrés Patricio Morales Tipán; Olmedo Xavier Ruiz Lara; Cristian Manuel Chango Checa

desechos no se eliminen de forma eficiente, lo que da origen a una infección renal en la persona diabética, que se le conoce por nefropatía diabética. Cuando se presenta esta enfermedad renal el paciente requerirá de diálisis o, en el peor de los casos, de un trasplante de riñones.

4. Neuropatía o trastorno neuropático. Esta patología se cree que es el resultado de una lesión microvascular diabética que involucra los vasos sanguíneos menores que irrigan los nervios, por lo que provoca serios daños en ellos. Una persona diabética debe tomar precauciones con tal de no sufrir problemas en el sistema circulatorio y nervioso. Los primeros en padecer los daños son los nervios de las piernas y pasado un tiempo los de los brazos y manos. El dolor y el adormecimiento son los síntomas más comunes de esta neuropatía periférica. Igualmente existe la neuropatía anatómica, que provoca lesiones en los nervios que mantienen el correcto funcionamiento de la digestión, micción y función sexual.

5. Disfunción sexual. El incorrecto control de la glucemia en sangre por elevados períodos de tiempo provoca algunas lesiones en los sistemas circulatorios y nerviosos, lo que puede llevar a que los hombres presenten dificultades en la erección.

6. Daños psicológicos y sociales. Producto de que la diabetes es una enfermedad que afecta tanto al entorno familiar y no únicamente al paciente, esta es la consecuencia que más comúnmente se puede apreciar, puesto que los familiares se ven involucrados de distintas maneras. 


\section{Factores de riesgo que inciden en la presencia de diabetes}

Vol. 2, núm. 4., (2018)

Andrea Carolina Mariño Jara; Mary Isabel Vinces Zambrano; Andrea Natacha Pico Tagle; Andrés Patricio Morales Tipán; Olmedo Xavier Ruiz Lara; Cristian Manuel Chango Checa

7. Ateroesclerosis. Es un síndrome caracterizado por el depósito e infiltración de sustancias lipídicas en las paredes de las arterias de mediano y grueso calibre. En enfermos diabéticos hace que la sangre fluya de una manera inadecuada, producto del depósito de grasas en las arterias del cuerpo, lo que produce problemas en el cerebro, en el corazón y en las extremidades.

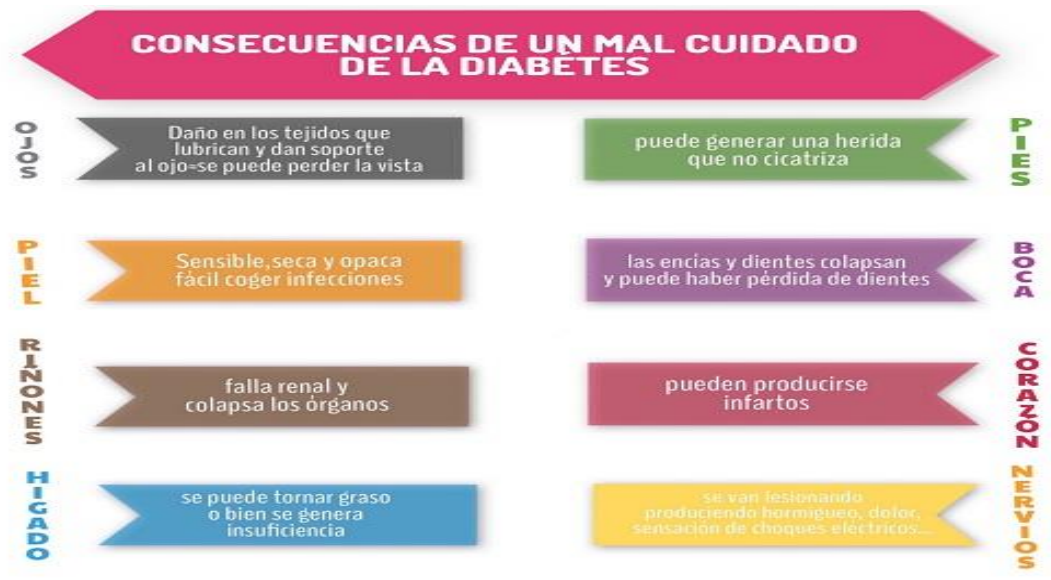

\section{La diabetes puede afectar de diferentes maneras el organismo del enfermo}

\section{Factores de riesgo para la diabetes tipo 2 (8)}

La probabilidad de que desarrolle diabetes tipo 2 depende de una combinación de factores de riesgo, como los genes y el estilo de vida. Aunque no se pueden cambiar ciertos factores de riesgo como los antecedentes familiares, la edad o el origen étnico, sí se pueden cambiar los que tienen que ver con la alimentación, la actividad física y el peso. Estos cambios en el estilo de vida pueden afectar la probabilidad de desarrollar diabetes tipo 2 . 


\section{Factores de riesgo que inciden en la presencia de diabetes}

Vol. 2, núm. 4., (2018)

Andrea Carolina Mariño Jara; Mary Isabel Vinces Zambrano; Andrea Natacha Pico Tagle; Andrés Patricio Morales Tipán; Olmedo Xavier Ruiz Lara; Cristian Manuel Chango Checa

A continuación, se da una lista de los factores de riesgo de la diabetes tipo 2 y usted puede ver cuáles aplican a su caso. Si toma medidas con respecto a los factores que puede cambiar, puede retrasar o prevenir la diabetes tipo 2 .

Una persona tiene más probabilidad de desarrollar diabetes tipo 2 si:

- $\quad$ tiene sobrepeso u obesidad

- $\quad$ tiene más de 45 años de edad

- $\quad$ tiene antecedentes familiares de diabetes

- es afroamericana, nativa de Alaska, indígena estadounidense, estadounidense de origen asiático, hispana/latina, nativa de Hawái, o de las Islas del Pacífico.

- $\quad$ tiene la presión arterial alta

- tienen un nivel bajo de colesterol HDL (“el colesterol bueno") o un nivel alto de triglicéridos

- $\quad$ tienen antecedentes de diabetes gestacional o dio a luz a un bebé que pesó más de 9 libras

- $\quad$ no se mantiene físicamente activa

- tiene antecedentes de enfermedades del corazón o accidentes cardiovasculares 


\section{Factores de riesgo que inciden en la presencia de diabetes}

Vol. 2, núm. 4., (2018)

Andrea Carolina Mariño Jara; Mary Isabel Vinces Zambrano; Andrea Natacha Pico Tagle;

Andrés Patricio Morales Tipán; Olmedo Xavier Ruiz Lara; Cristian Manuel Chango Checa

- $\quad$ tiene depresión

- $\quad$ tiene síndrome de ovario poliquístico

- tiene acantosis nigricans, zonas de piel oscura, gruesa y aterciopelada alrededor del cuello o las axilas

También puede tomar el examen de riesgo de la diabetes para conocer su riesgo de sufrir de diabetes tipo 2.

Para ver si su peso lo pone en riesgo de desarrollar diabetes tipo 2, busque su estatura en los siguientes gráficos de índice de masa corporal (IMC). Si su peso es igual o mayor que el mencionado, su probabilidad de desarrollar la enfermedad es mayor.

\section{¿Qué puedo hacer para prevenir la diabetes tipo 2?}

Usted puede ayudar a prevenir o retardar la diabetes tipo 2 bajando de peso si tiene sobrepeso, consumiendo menos calorías y haciendo más actividad física.

Hable con su médico acerca de cualquiera de las afecciones arriba mencionadas que podrían requerir tratamiento médico. El manejo de estos problemas de salud puede ayudar a reducir su probabilidad de desarrollar diabetes tipo 2. Además, pregúntele a su médico acerca de las medicinas que usted toma que pueden aumentar su riesgo.

\section{Pruebas y diagnóstico de la diabetes}




\section{Factores de riesgo que inciden en la presencia de diabetes}

Vol. 2, núm. 4., (2018)

Andrea Carolina Mariño Jara; Mary Isabel Vinces Zambrano; Andrea Natacha Pico Tagle; Andrés Patricio Morales Tipán; Olmedo Xavier Ruiz Lara; Cristian Manuel Chango Checa

Su médico, u otro profesional de la salud, pueden diagnosticar la diabetes, la prediabetes, y la diabetes gestacional por medio de análisis de sangre. Los análisis de sangre muestran si el nivel de glucosa en la sangre, también llamada azúcar en la sangre, está demasiado alto.

No intente diagnosticarse usted mismo si piensa que puede tener diabetes. Los equipos que se pueden comprar sin receta médica, como los glucómetros, no pueden diagnosticar la diabetes.

\section{¿A quién se le deben hacer las pruebas para detectar la diabetes?}

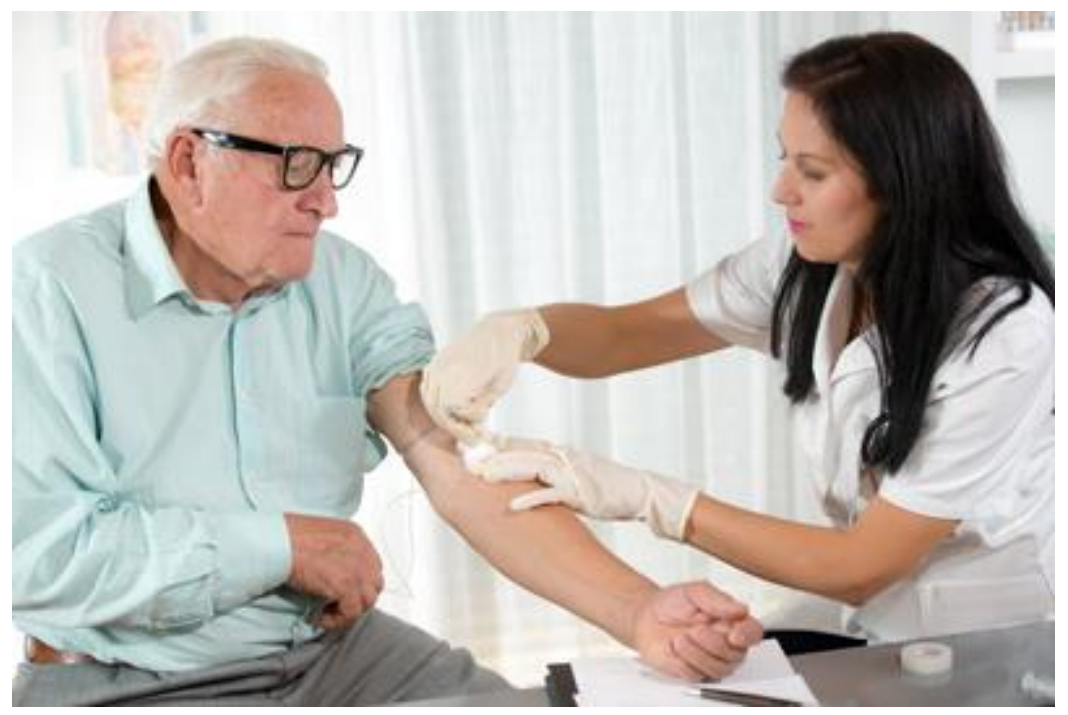

Los análisis de sangre les ayudan a los profesionales de la salud a hacer el diagnóstico de la diabetes y la prediabetes.

Cualquier persona que tenga síntomas de diabetes debe ser examinada para detectar la enfermedad. Algunas personas no tendrán síntomas, pero pueden tener factores de riesgo para diabetes y deben ser examinadas. Las pruebas les permiten a los profesionales de la salud 


\section{Factores de riesgo que inciden en la presencia de diabetes}

Vol. 2, núm. 4., (2018)

Andrea Carolina Mariño Jara; Mary Isabel Vinces Zambrano; Andrea Natacha Pico Tagle; Andrés Patricio Morales Tipán; Olmedo Xavier Ruiz Lara; Cristian Manuel Chango Checa

detectar la diabetes más temprano y trabajar con sus pacientes para manejar la enfermedad y prevenir sus complicaciones.

Las pruebas también les permiten a los profesionales de la salud detectar la prediabetes. Los cambios del estilo de vida encaminados a perder una cantidad moderada de peso, si se tiene sobrepeso, pueden ayudar a retardar o prevenir la diabetes tipo 2.

\section{Diabetes tipo 1}

Casi siempre se hacen las pruebas para detectar la diabetes tipo 1 a personas que tienen síntomas de la enfermedad. Los médicos suelen diagnosticar la diabetes tipo 1 en niños y adultos jóvenes. Debido a que la diabetes tipo 1 puede ser hereditaria, un estudio denominado TrialNet ofrece pruebas a miembros de la familia de personas que sufren la enfermedad, incluso si no tienen síntomas.

\section{Diabetes tipo 2}

Los expertos recomiendan hacer las pruebas de rutina para detectar la diabetes tipo 2 si:

- $\quad$ tiene más de 45 años de edad o

- $\quad$ tiene entre 19 y 44 años, sobrepeso u obesidad y uno o más de los factores de riesgo de diabetes 


\section{Factores de riesgo que inciden en la presencia de diabetes}

Vol. 2, núm. 4., (2018)

Andrea Carolina Mariño Jara; Mary Isabel Vinces Zambrano; Andrea Natacha Pico Tagle;

Andrés Patricio Morales Tipán; Olmedo Xavier Ruiz Lara; Cristian Manuel Chango Checa

$$
\text { - } \quad \text { es una mujer que ha tenido diabetes gestacional }{ }^{3}
$$

Medicare cubre el costo de las pruebas para el diagnóstico de la diabetes para las personas que tienen ciertos factores de riesgo para esta enfermedad. Si usted tiene Medicare, averigüe si cumple los requisitos para la cobertura . Si tiene otro seguro, pregúntele a su compañía de seguros si le cubre las pruebas de detección de la diabetes.

Aunque la diabetes tipo 2 se presenta con mayor frecuencia en los adultos, también se puede presentar en los niños. Los expertos recomiendan hacer las pruebas de detección a los niños entre los 10 y 18 años de edad que tienen sobrepeso u obesidad y al menos dos de estos otros factores de riesgo de diabetes: ${ }^{3}$

- $\quad$ bajo peso al nacer

- $\quad$ su madre tuvo diabetes durante su embarazo

- cualquier factor de riesgo mencionado en los factores de riesgo para diabetes tipo 2

\section{Diabetes gestacional}

A todas las mujeres embarazadas que no tienen diagnóstico previo de diabetes se les debe hacer un examen de detección de la diabetes gestacional. Si usted está embarazada, deberá hacerse una prueba de tolerancia a la glucosa entre las 24 y las 28 semanas de embarazo. ${ }^{3}$

\section{¿Qué pruebas se usan para diagnosticar la diabetes y la prediabetes?}




\section{Factores de riesgo que inciden en la presencia de diabetes}

Vol. 2, núm. 4., (2018)

Andrea Carolina Mariño Jara; Mary Isabel Vinces Zambrano; Andrea Natacha Pico Tagle;

Andrés Patricio Morales Tipán; Olmedo Xavier Ruiz Lara; Cristian Manuel Chango Checa

La mayoría de los profesionales de la salud suelen usar la glucosa plasmática en ayunas o la prueba A1C para el diagnóstico de la diabetes. En algunos casos, pueden ordenar una glucosa plasmática aleatoria.

\section{Glucosa plasmática en ayunas}

La glucosa plasmática en ayunas es una prueba que mide el nivel de glucosa en la sangre en un momento concreto. Para conseguir los resultados más fiables, lo mejor es hacer el examen por la mañana, después de un ayuno de por lo menos 8 horas. Ayunar significa no comer o beber nada más que unos pocos sorbos agua.

\section{Prueba A1C (9)}

La A1C es un análisis de sangre que indica los niveles promedio de glucosa en la sangre (azúcar en la sangre) durante los últimos 3 meses. Otros nombres para la prueba A1C son prueba de la hemoglobina A1c, HbA1C y hemoglobina glucosilada. Usted puede comer y beber antes de este examen. Cuando el médico usa la A1C para diagnosticar la diabetes, tiene en cuenta factores como la edad y la presencia de anemia o algún otro problema de la sangre. ${ }^{3}$ La prueba A1C no da resultados precisos en las personas con anemia.

Su médico u otro miembro de su equipo de atención médica le informará el resultado de la prueba $\mathrm{A} 1 \mathrm{C}$ en forma de porcentaje, por ejemplo, un $\mathrm{A} 1 \mathrm{C}$ del 7 por ciento. Cuanto más alto sea el porcentaje, más alto será el promedio de los niveles de glucosa en la sangre en los últimos tres meses. 


\section{Factores de riesgo que inciden en la presencia de diabetes}

Vol. 2, núm. 4., (2018)

Andrea Carolina Mariño Jara; Mary Isabel Vinces Zambrano; Andrea Natacha Pico Tagle;

Andrés Patricio Morales Tipán; Olmedo Xavier Ruiz Lara; Cristian Manuel Chango Checa

Las personas con diabetes también usan la información de la prueba A1C para ayudar a controlar su enfermedad.

\section{Prueba de glucosa plasmática aleatoria (o glucemia aleatoria)}

En ocasiones, los profesionales de la salud utilizan esta prueba para diagnosticar la diabetes cuando hay síntomas y no quieren esperar a que la persona tenga ocho horas de ayuno. No es necesario el ayuno nocturno para esta prueba, porque se puede hacer en cualquier momento.

\section{¿Qué pruebas se utilizan para diagnosticar la diabetes gestacional?}

Las mujeres embarazadas pueden hacerse la prueba de sobrecarga oral de glucosa, la prueba de tolerancia oral a la glucosa, o ambas. Estas pruebas muestran cómo el organismo maneja la glucosa.

\section{Prueba de sobrecarga oral de glucosa}

Si usted está embarazada y un profesional de la salud quiere saber si tiene diabetes gestacional, puede ordenarle primero una prueba de sobrecarga oral de glucosa. Otros nombres para este examen son la prueba de detección de la diabetes gestacional o el test de O’Sullivan. En esta prueba, el médico le tomará la muestra de sangre una hora después de haber tomado un líquido dulce que contiene glucosa. No es necesario estar en ayunas para este examen. Si su nivel 


\section{Factores de riesgo que inciden en la presencia de diabetes}

Vol. 2, núm. 4., (2018)

Andrea Carolina Mariño Jara; Mary Isabel Vinces Zambrano; Andrea Natacha Pico Tagle;

Andrés Patricio Morales Tipán; Olmedo Xavier Ruiz Lara; Cristian Manuel Chango Checa

de glucosa en la sangre es demasiado alto (135 a 140 o más), es posible que le pidan que regrese en ayunas para una prueba de tolerancia oral a la glucosa.

\section{Prueba de tolerancia oral a la glucosa}

La prueba de tolerancia oral a la glucosa mide la glucosa en la sangre después de haber guardado ayuno durante por lo menos 8 horas. Primero, un profesional de la salud le tomará una muestra de sangre en ayunas y luego le dará a beber un líquido que contiene glucosa. Para hacer el diagnóstico de la diabetes gestacional hay que volver a obtener una muestra de sangre cada hora durante 2 a 3 horas.

Si los niveles de glucosa en la sangre están elevados en dos o más muestras de la prueba de tolerancia oral a la glucosa, es decir, en ayunas, a la hora, a las 2 horas o a las 3 horas, usted tiene diabetes gestacional. El equipo de atención médica le explicará los resultados de la prueba.

Los profesionales de la salud también pueden utilizar esta prueba para diagnosticar la diabetes tipo 2 y la prediabetes en personas que no están embarazadas. La prueba de tolerancia oral a la glucosa ayuda a los profesionales de la salud a detectar la diabetes tipo 2 y la prediabetes mejor que la prueba de glucosa plasmática en ayunas, pero es una prueba más costosa y no es tan fácil de realizar. Para hacer el diagnóstico de diabetes tipo 2 y prediabetes, un profesional de la salud tendrá que obtener una muestra de sangre una hora después de beber el líquido que contiene glucosa y nuevamente después de 2 horas.

\section{¿Qué valores de esta prueba indican si tengo diabetes o prediabetes?}




\section{Factores de riesgo que inciden en la presencia de diabetes}

Vol. 2, núm. 4., (2018)

Andrea Carolina Mariño Jara; Mary Isabel Vinces Zambrano; Andrea Natacha Pico Tagle; Andrés Patricio Morales Tipán; Olmedo Xavier Ruiz Lara; Cristian Manuel Chango Checa

Todas las pruebas para detectar la diabetes y la prediabetes utilizan una medida distinta.

Por lo general, el mismo método de prueba tiene que repetirse otro día para hacer el diagnóstico de diabetes. El médico también puede utilizar un segundo método de prueba para confirmar el diagnóstico.

La siguiente tabla le ayudará a comprender qué significan los valores de su prueba, si usted no está embarazada.

${ }^{\text {a }}$ Los valores de glucosa se dan en miligramos por decilitro $(\mathrm{mg} / \mathrm{dL})$.

${ }^{\mathrm{b}}$ Dos horas después de tomar 75 gramos de glucosa. Para diagnosticar la diabetes gestacional, los profesionales de la salud dan más glucosa y utilizan diferentes valores como puntos de corte.

Fuente: Adaptado de la American Diabetes Association. Classification and diagnosis of diabetes. Diabetes Care.2016;39(1):S14-S20, Tablas 2.1, 2.3.

\begin{tabular}{|l|l|l|l|l|l}
\hline & A1C & Glucosa & Prueba de tolerancia & Prueba de glucosa \\
Diagnóstico & plasmática en & oral a la glucosa & plasmática aleatoria \\
(porcentaje) & ayunas (GPA) & $(\text { PTOG })^{\text {ab }}$ & $($ GPa $)$
\end{tabular}




\section{Factores de riesgo que inciden en la presencia de diabetes}

Vol. 2, núm. 4., (2018)

Andrea Carolina Mariño Jara; Mary Isabel Vinces Zambrano; Andrea Natacha Pico Tagle;

Andrés Patricio Morales Tipán; Olmedo Xavier Ruiz Lara; Cristian Manuel Chango Checa

\begin{tabular}{|l|l|l|l|l|}
\hline Normal & $\begin{array}{l}\text { Por debajo de } \\
5.7\end{array}$ & Por debajo de 99 & Por debajo de 139 & \\
\hline Prediabetes & 5.7 a 6.4 & 100 a 125 & 140 a 199 & \\
\hline Diabetes & Por $\quad$ encima & Por encima de & Por encima de 200 & Por encima de 200 \\
\hline & de 6.5 & 126 & & \\
\hline
\end{tabular}

\section{¿Cuáles pruebas ayudan a mi médico a saber qué tipo de diabetes tengo?}

Aunque las pruebas aquí descritas pueden confirmar que usted tiene diabetes, no pueden identificar de qué tipo. A veces los profesionales de la salud no están seguros si la diabetes es del tipo 1 o del tipo 2. La diabetes monogénica, un tipo raro de diabetes que puede afectar a los bebés, también se puede confundir con la diabetes tipo 1. El tratamiento depende del tipo de diabetes y, por lo tanto, es importante saber el tipo.

Para averiguar si su diabetes es de tipo 1, el profesional de la salud puede buscar ciertos auto anticuerpos. Los auto anticuerpos son anticuerpos que atacan por error las células y los tejidos sanos. La presencia de uno o más de los varios tipos de auto anticuerpos específicos de la diabetes es frecuente en la diabetes tipo 1, pero no en el tipo 2 ni en la diabetes monogénica. Un profesional de la salud tendrá que tomarle muestras de sangre para esta prueba. 


\section{Factores de riesgo que inciden en la presencia de diabetes}

Vol. 2, núm. 4., (2018)

Andrea Carolina Mariño Jara; Mary Isabel Vinces Zambrano; Andrea Natacha Pico Tagle;

Andrés Patricio Morales Tipán; Olmedo Xavier Ruiz Lara; Cristian Manuel Chango Checa

\section{Nutrición, alimentación y actividad física si se tiene diabetes}

La nutrición y la actividad física son partes importantes de un estilo de vida saludable para las personas con diabetes. Además de otros beneficios, seguir un plan de alimentación saludable y mantenerse físicamente activo puede ayudarle a mantener su nivel de glucosa en la sangre dentro de los límites deseados. Para manejar su nivel de glucosa en la sangre tiene que equilibrar lo que come y bebe con la actividad física y las medicinas para la diabetes, si los usa. Qué, cuánto y cuándo comer es importante para mantener su nivel de glucemia dentro de los límites recomendados por su equipo de atención médica.

Aumentar su actividad física y hacer cambios en lo que usted come y bebe puede parecerle difícil al principio. Tal vez le resulte más fácil si comienza con pequeños cambios y obtiene la ayuda de su familia, sus amigos y su equipo de atención médica.

Alimentarse bien y hacer actividad física casi todos los días de la semana puede ayudarle a:

- $\quad$ mantener sus niveles de glucosa en la sangre, presión arterial y colesterol dentro de los valores deseados

- bajar de peso o mantener un peso saludable

- $\quad$ prevenir o retrasar los problemas de la diabetes

- $\quad$ sentirse bien y tener más energía

\section{¿Qué puedo comer si tengo diabetes?}




\section{Factores de riesgo que inciden en la presencia de diabetes}

Vol. 2, núm. 4., (2018)

Andrea Carolina Mariño Jara; Mary Isabel Vinces Zambrano; Andrea Natacha Pico Tagle; Andrés Patricio Morales Tipán; Olmedo Xavier Ruiz Lara; Cristian Manuel Chango Checa

Quizás piense que tener diabetes significa que no va a poder consumir los alimentos que le gustan. La buena noticia es que usted puede comer sus alimentos preferidos, pero es posible que tenga que hacerlo en porciones más pequeñas o con menos frecuencia. Su equipo de atención médica le ayudará a crear un plan de alimentación para personas con diabetes que satisfaga sus necesidades y sus gustos.

La clave en la diabetes es consumir una variedad de alimentos saludables de todos los grupos, en las cantidades establecidas en su plan de alimentación.

Los grupos de alimentos son:

\section{- $\quad$ verduras}

○ no feculentas (sin almidón): incluyen brócoli, zanahorias, vegetales de hojas verdes, pimientos y tomates

○ feculentas (ricas en almidón): incluye papas, maíz y arvejas (chícharos)

- $\quad$ frutas - incluye naranjas, melones, fresas, manzanas, bananos y uvas

- $\quad$ granos - por lo menos la mitad de los granos del día deben ser integrales

○ incluye trigo, arroz, avena, maíz, cebada y quinua

- ejemplos: pan, pasta, cereales y tortillas 


\section{Factores de riesgo que inciden en la presencia de diabetes}

Vol. 2, núm. 4., (2018)

Andrea Carolina Mariño Jara; Mary Isabel Vinces Zambrano; Andrea Natacha Pico Tagle;

Andrés Patricio Morales Tipán; Olmedo Xavier Ruiz Lara; Cristian Manuel Chango Checa

\section{- $\quad$ proteínas}

- carne magra (con poca grasa)

- pollo o pavo sin el pellejo

○ pescado

$\circ$ huevos

○ nueces y maní

- fríjoles secos y otras leguminosas como garbanzos y guisantes

partidos

- Sustitutos de la carne, como el tofu

- $\quad$ lácteos descremados o bajos en grasa

$\circ \quad$ leche o leche sin lactosa si usted tiene intolerancia a la lactosa

$\circ$ yogur

$\circ \quad$ queso

Aprenda más sobre los grupos de alimentos del Departamento de Agricultura de los Estados Unidos (USDA) ChooseMyPlate.gov (con información en español).

Consuma alimentos que tengan grasas saludables para el corazón, provenientes principalmente de estas fuentes: 


\section{Factores de riesgo que inciden en la presencia de diabetes}

Vol. 2, núm. 4., (2018)

Andrea Carolina Mariño Jara; Mary Isabel Vinces Zambrano; Andrea Natacha Pico Tagle;

Andrés Patricio Morales Tipán; Olmedo Xavier Ruiz Lara; Cristian Manuel Chango Checa

- $\quad$ aceites que se mantienen líquidos a temperatura ambiente, como el de canola y el de oliva

- $\quad$ nueces y semillas

- $\quad$ pescados saludables para el corazón, como salmón, atún y caballa

- aguacate

Para cocinar use aceite en lugar de mantequilla, crema de leche, manteca de cerdo o margarina sólida.

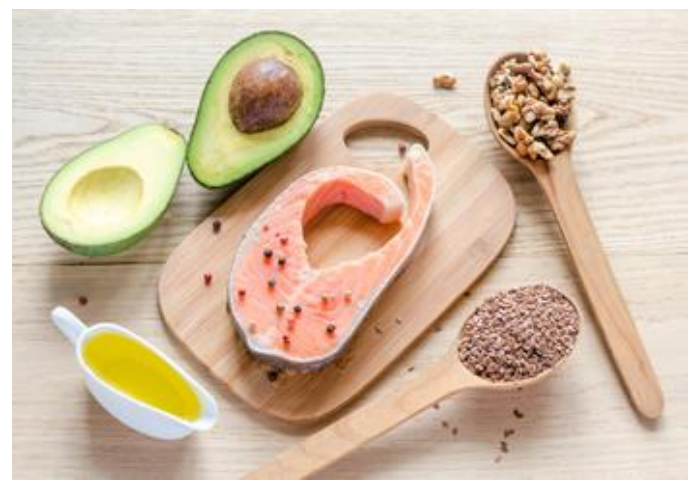

Elija grasas saludables, como nueces, semillas y aceite de oliva

\section{¿Qué alimentos y bebidas debo limitar si tengo diabetes?}

Los alimentos y bebidas que hay que limitar incluyen:

- $\quad$ alimentos fritos y otros ricos en grasas saturadas y grasas trans

- alimentos con alto contenido de sal, también llamado sodio 


\section{Factores de riesgo que inciden en la presencia de diabetes}

Vol. 2, núm. 4., (2018)

Andrea Carolina Mariño Jara; Mary Isabel Vinces Zambrano; Andrea Natacha Pico Tagle;

Andrés Patricio Morales Tipán; Olmedo Xavier Ruiz Lara; Cristian Manuel Chango Checa

- $\quad$ dulces, como productos horneados, dulces y helados

- $\quad$ bebidas con azúcares agregados, como jugos, gaseosas y bebidas regulares

para deporte o energéticas

Tome agua en vez de bebidas azucaradas. Considere la posibilidad de usar un sustituto del azúcar en su café o té.

Si toma alcohol, hágalo con moderación. Esto quiere decir, no más de un trago al día si es mujer o dos tragos al día si es hombre. Si usa insulina o medicinas para la diabetes que aumentan la cantidad de insulina que el cuerpo produce, el alcohol puede hacer que su nivel de glucosa en la sangre baje demasiado. Esto es especialmente cierto si usted no ha comido hace algún tiempo. Es mejor comer algo cuando toma alcohol.

\section{¿Cuándo debo comer si tengo diabetes?}

Algunas personas con diabetes tienen que comer casi a la misma hora todos los días. Otras pueden ser más flexibles con el horario de sus comidas. Dependiendo de sus medicinas para la diabetes o el tipo de insulina que use, es posible que tenga que consumir la misma cantidad de carbohidratos todos los días a la misma hora.

Si usted usa insulina "a la hora de comer", sus horarios de comidas pueden ser más flexibles. 


\section{Factores de riesgo que inciden en la presencia de diabetes}

Vol. 2, núm. 4., (2018)

Andrea Carolina Mariño Jara; Mary Isabel Vinces Zambrano; Andrea Natacha Pico Tagle;

Andrés Patricio Morales Tipán; Olmedo Xavier Ruiz Lara; Cristian Manuel Chango Checa

Si usa insulina o ciertas medicinas para la diabetes y omite o retrasa una comida, su nivel de glucosa en la sangre puede bajar demasiado. Pregúntele a su equipo de atención médica cuándo debe comer y si debe hacerlo antes y después de hacer una actividad física.

\section{¿Cuánto puedo comer si tengo diabetes?}

Consumir la cantidad adecuada de alimentos también le ayudará a manejar su glucemia y su peso. Su equipo de atención médica puede ayudarle a definir cuánta comida y cuántas calorías debe consumir cada día.

\section{Planificación de la pérdida de peso}

Si usted tiene sobrepeso o tiene obesidad, trabaje con su equipo de atención médica para establecer un plan para perder peso.

El Planificador para Adelgazar (en inglés) puede ayudarle a adaptar sus planes de actividad física y planes de calorías para alcanzar y mantener su peso deseado.

Para adelgazar es necesario usted tiene que consumir menos calorías y reemplazar los alimentos menos saludables por alimentos bajos en calorías, grasas y azúcar.

Si usted tiene diabetes, sobrepeso u obesidad y está pensando en tener un bebé, debe tratar de perder el exceso de peso antes de quedar embarazada. Aprenda más sobre el embarazo y la diabetes.

\section{Métodos para planificar las comidas}




\section{Factores de riesgo que inciden en la presencia de diabetes}

Vol. 2, núm. 4., (2018)

Andrea Carolina Mariño Jara; Mary Isabel Vinces Zambrano; Andrea Natacha Pico Tagle;

Andrés Patricio Morales Tipán; Olmedo Xavier Ruiz Lara; Cristian Manuel Chango Checa

Dos métodos que se usan con frecuencia para ayudar a planificar cuánto comer si se tiene diabetes son el método del plato y el conteo de carbohidratos (también llamados hidratos de carbono). Consulte con su equipo de atención médica sobre el método que más le convenga.

\section{Método del plato}

El método del plato le ayuda a controlar el tamaño de sus porciones. No tiene que contar calorías. El método le muestra la cantidad de cada grupo de alimentos que debe comer y funciona mejor para el almuerzo y la cena.

Utilice un plato de 9 pulgadas $(15 \mathrm{~cm})$ de diámetro. Llene la mitad del plato con las verduras sin almidón, en un cuarto del plato coloque una carne u otra proteína y en el último cuarto del plato ponga los granos u otro tipo de fuente de almidón. Las fuentes de almidón incluyen verduras feculentas como el maíz y los guisantes.

También puede comer una taza pequeña de fruta o un pedazo de fruta y tomar un vaso pequeño de leche si está incluido en su plan de alimentación. 


\section{Factores de riesgo que inciden en la presencia de diabetes}

Vol. 2, núm. 4., (2018)

Andrea Carolina Mariño Jara; Mary Isabel Vinces Zambrano; Andrea Natacha Pico Tagle; Andrés Patricio Morales Tipán; Olmedo Xavier Ruiz Lara; Cristian Manuel Chango Checa

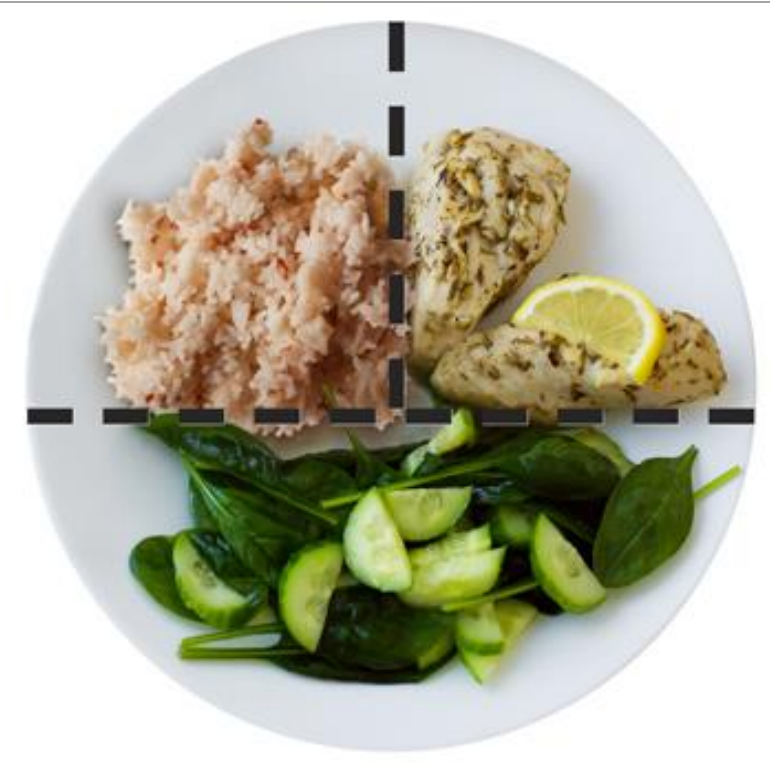

El método del plato muestra la cantidad de cada grupo de alimentos que debe comer

Puede encontrar muchas combinaciones distintas de alimentos y más detalles sobre el método del plato en el recurso Crear tu plato de la Asociación Americana de la Diabetes.

Su plan de alimentación diaria también puede incluir pequeños refrigerios entre las comidas.

\section{Tamaños de las porciones}

Puede utilizar objetos cotidianos o su mano para calcular el tamaño de una porción.

- 1 porción de carne o pollo equivale a la palma de su mano o a una baraja

de cartas

- 1 porción de 3 onzas (100 g) de pescado equivale al tamaño de una chequera 


\section{Factores de riesgo que inciden en la presencia de diabetes}

Vol. 2, núm. 4., (2018)

Andrea Carolina Mariño Jara; Mary Isabel Vinces Zambrano; Andrea Natacha Pico Tagle; Andrés Patricio Morales Tipán; Olmedo Xavier Ruiz Lara; Cristian Manuel Chango Checa

- 1 porción de queso equivale a seis dados

- $\quad 1 / 2$ taza de pasta o de arroz cocinado equivale a un puñado o al tamaño de una pelota de tenis

- 1 porción de panqueque o waffle equivale al tamaño de un DVD

- 2 cucharadas de mantequilla de maní equivalen al tamaño de una pelota de ping-pong.

\section{Conteo de carbohidratos}

El conteo de carbohidratos implica llevar un registro de la cantidad de carbohidratos que usted consume cada día. Dado que los carbohidratos se transforman en glucosa en el cuerpo, estos afectan su nivel de glucosa en la sangre más que otros alimentos. El conteo de carbohidratos puede ayudarle a controlar su glucosa en la sangre. Si usted usa insulina, contar los carbohidratos puede ayudarle a determinar la dosis adecuada.

La cantidad correcta de carbohidratos varía de acuerdo a cómo maneja la diabetes, e incluye cuánta actividad física hace y que medicinas toma, si es del caso. Su equipo de atención médica puede ayudarle a crear un plan de alimentación personal basado en el conteo de carbohidratos.

La cantidad de carbohidratos en los alimentos se mide en gramos. Para contar los gramos de carbohidratos en los alimentos, necesitará:

- $\quad$ saber cuáles alimentos contienen carbohidratos 


\section{Factores de riesgo que inciden en la presencia de diabetes}

Vol. 2, núm. 4., (2018)

Andrea Carolina Mariño Jara; Mary Isabel Vinces Zambrano; Andrea Natacha Pico Tagle; Andrés Patricio Morales Tipán; Olmedo Xavier Ruiz Lara; Cristian Manuel Chango Checa

- $\quad$ leer la etiqueta de contenido nutricional, o aprender a calcular la cantidad

de gramos de carbohidratos en los alimentos que consume

- $\quad$ sumar los gramos de carbohidratos en cada alimento para obtener el total de carbohidratos para cada comida y para el día

La mayoría de los carbohidratos proviene de los almidones, las frutas, la leche y los dulces. Trate de limitar los carbohidratos que tienen azúcares agregados o granos refinados, como el pan blanco y el arroz blanco. En lugar de ellos consuma los carbohidratos de las frutas, verduras, granos enteros, leguminosas y leche descremada o baja en grasa.

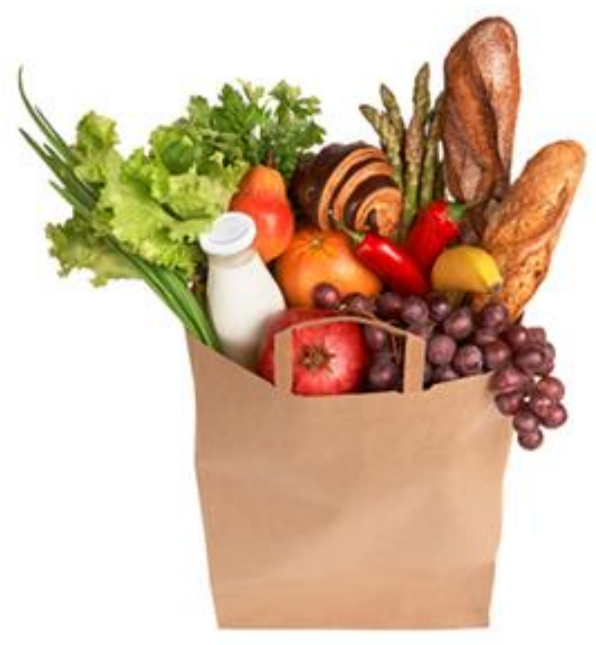

Elija carbohidratos saludables, como frutas, verduras, granos enteros, leguminosas y leche baja en grasa, como parte de su plan de alimentación. 


\section{Factores de riesgo que inciden en la presencia de diabetes}

Vol. 2, núm. 4., (2018)

Andrea Carolina Mariño Jara; Mary Isabel Vinces Zambrano; Andrea Natacha Pico Tagle;

Andrés Patricio Morales Tipán; Olmedo Xavier Ruiz Lara; Cristian Manuel Chango Checa

Además de utilizar el método del plato y el conteo de carbohidratos, puede consultar con un nutricionista o dietista registrado quien le indicará las opciones de terapia de nutrición médica.

\section{¿Qué es la terapia de nutrición médica?}

La terapia de nutrición médica es un servicio que prestan los nutricionistas o dietistas registrados para crear planes de alimentación personalizados con base en sus necesidades y gustos. Se ha demostrado que la terapia de nutrición médica mejora el manejo de la diabetes. Medicare paga la terapia de nutrición médica para las personas con diabetes . Si usted tiene un seguro diferente al de Medicare, pregunte si le cubre la terapia de nutrición médica para la diabetes.

\section{¿Me ayudan con la diabetes los suplementos y las vitaminas?}

No hay pruebas claras de que el consumo de suplementos dietéticos como vitaminas, minerales, hierbas o especias pueda ayudar al manejo de la diabetes. ${ }^{6}$ Es posible que necesite suplementos si no puede obtener la cantidad suficiente de vitaminas y minerales de los alimentos. Hable con su médico antes de tomar cualquier suplemento, ya que algunos pueden causar efectos secundarios o alterar el efecto de las medicinas. ${ }^{7}$

\section{¿Por qué debo hacer actividad física si tengo diabetes?}




\section{Factores de riesgo que inciden en la presencia de diabetes}

Vol. 2, núm. 4., (2018)

Andrea Carolina Mariño Jara; Mary Isabel Vinces Zambrano; Andrea Natacha Pico Tagle; Andrés Patricio Morales Tipán; Olmedo Xavier Ruiz Lara; Cristian Manuel Chango Checa

La actividad física es importante para el control de los niveles de glucosa en la sangre y para mantenerse saludable. La actividad física tiene muchos beneficios para la salud.

La actividad física:

- $\quad$ reduce los niveles de glucosa en la sangre

- $\quad$ baja la presión arterial

- mejora la circulación de la sangre

- $\quad$ quema calorías adicionales para que pueda mantener su peso controlado si es necesario

- $\quad$ mejora su estado de ánimo

- $\quad$ puede prevenir caídas y mejorar la memoria en los adultos mayores

- $\quad$ puede ayudarle a dormir mejor

Si usted tiene sobrepeso, combinar la actividad física con un plan de alimentación con reducción de calorías puede tener aún más ventajas. En el estudio Look AHEAD: Action for Health in Diabetes ${ }^{6}$ (en inglés), los adultos obesos con diabetes tipo 2 que comieron menos y se movieron más obtuvieron mayores beneficios para la salud a largo plazo que los que no hicieron estos cambios. Estas ventajas incluyen mejores niveles de colesterol, menos apnea del sueño, y mayor libertad de movimiento. 


\section{Factores de riesgo que inciden en la presencia de diabetes}

Vol. 2, núm. 4., (2018)

Andrea Carolina Mariño Jara; Mary Isabel Vinces Zambrano; Andrea Natacha Pico Tagle; Andrés Patricio Morales Tipán; Olmedo Xavier Ruiz Lara; Cristian Manuel Chango Checa

Incluso pequeñas cantidades de actividad física puede ayudar. Los expertos sugieren que se ponga una meta de por lo menos 30 minutos de actividad física moderada o vigorosa 5 días de la semana. ${ }^{8}$ La actividad moderada es un poco difícil y la actividad vigorosa es intensa y difícil. Si usted quiere perder peso o no recuperar el peso perdido es posible que tenga que hacer 60 minutos o más de actividad física 5 días a la semana. ${ }^{8}$

Tenga paciencia. Pueden pasar algunas semanas de hacer actividad física antes de que note los cambios en su salud.

\section{¿Cómo puedo mantenerme físicamente activo sin problemas si tengo diabetes?}

Asegúrese de tomar agua antes, durante y después de hacer ejercicio para mantenerse hidratado. A continuación, le damos otras sugerencias de actividades físicas seguras para personas con diabetes.

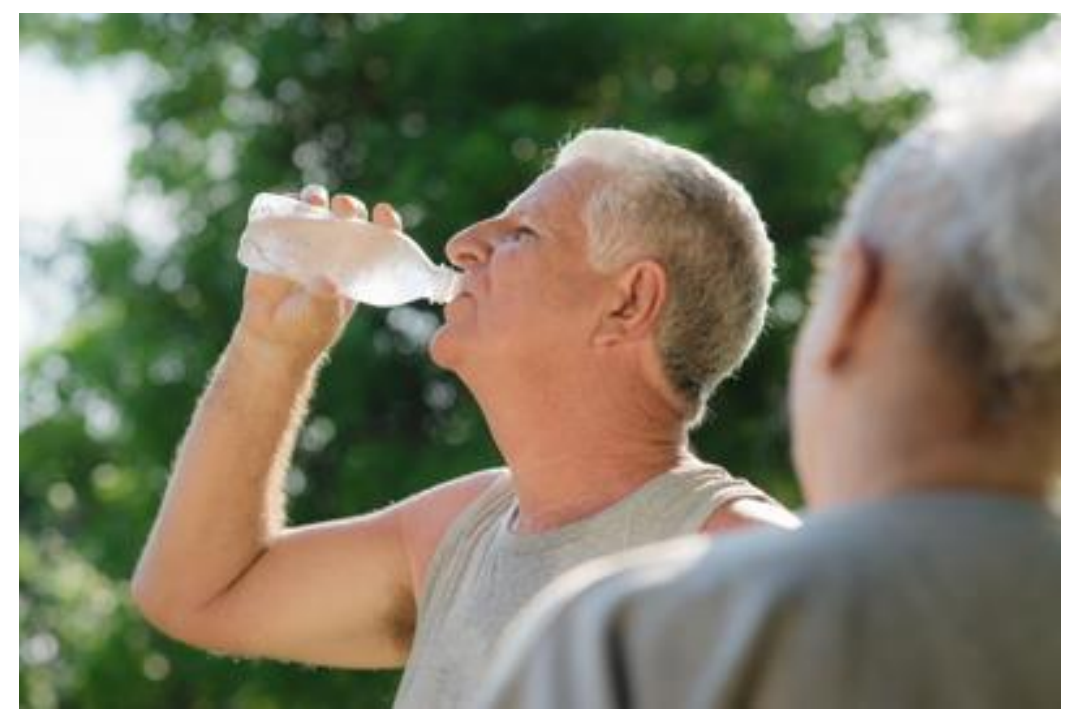

Tome agua cuando haga ejercicio para mantenerse hidratado 


\section{Factores de riesgo que inciden en la presencia de diabetes}

Vol. 2, núm. 4., (2018)

Andrea Carolina Mariño Jara; Mary Isabel Vinces Zambrano; Andrea Natacha Pico Tagle;

Andrés Patricio Morales Tipán; Olmedo Xavier Ruiz Lara; Cristian Manuel Chango Checa

\section{Planee su actividad física}

Hable con su equipo de atención médica antes de comenzar una nueva rutina de ejercicio, sobre todo si usted tiene otros problemas de salud. Su equipo de atención médica le dirá el intervalo los valores deseables para su nivel de glucosa en la sangre y le sugerirá cómo ejercitarse de manera segura.

Su equipo de atención médica también puede ayudarle a decidir el mejor momento del día para hacer ejercicio con base en su horario, su plan de alimentación y sus medicinas para la diabetes.

Si usa insulina tendrá que equilibrar la actividad que realice con sus dosis de insulina y con las comidas, para evitar que se le baje demasiado el nivel de glucosa en la sangre.

\section{Prevenga la hipoglucemia}

Dado que la actividad física reduce el nivel de glucosa en la sangre, usted debe protegerse contra la hipoglucemia. La hipoglucemia es más probable en las personas que usan insulina u otras medicinas para la diabetes, como las sulfonilureas. La hipoglucemia también puede presentarse después de un entrenamiento largo e intenso o si se omite una comida antes de hacer ejercicio. La hipoglucemia puede presentarse mientras se hace la actividad física o hasta 24 horas después. 


\section{Factores de riesgo que inciden en la presencia de diabetes}

Vol. 2, núm. 4., (2018)

Andrea Carolina Mariño Jara; Mary Isabel Vinces Zambrano; Andrea Natacha Pico Tagle;

Andrés Patricio Morales Tipán; Olmedo Xavier Ruiz Lara; Cristian Manuel Chango Checa

La planeación es clave para prevenir la hipoglucemia. Por ejemplo, si usted usa insulina, su médico le puede sugerir que baje la dosis o coma un pequeño refrigerio con carbohidratos antes, durante o después de la actividad física, especialmente si es intensa. ${ }^{9}$

Puede ser necesario medir el nivel de glucosa en la sangre antes, durante e inmediatamente después de la actividad física.

\section{No corra peligro cuando su nivel de glucosa en la sangre está alto}

Si usted tiene diabetes tipo 1, debe evitar la actividad física vigorosa si tiene cetonas en la sangre o la orina. Las cetonas son sustancias químicas que el cuerpo produce cuando su nivel de glucosa en la sangre está demasiado alto, es decir, cuando hay hiperglucemia, y su nivel de insulina está demasiado bajo. Si usted hace actividad física cuando tiene cetonas en la sangre o la orina, su glucosa en la sangre puede subir aún más. Pregúntele a su equipo de atención médica cuál es el nivel de cetonas peligroso en su caso y cómo detectarlas. Las cetonas no son comunes en las personas que tienen diabetes tipo 2 .

\section{Cuídese los pies}

Las personas con diabetes pueden tener problemas en los pies debido a la mala circulación de la sangre y a las lesiones de los nervios, que pueden ser el resultado de los altos niveles de glucosa en la sangre. Para ayudar a prevenir estos problemas, debe usar zapatos cómodos y con soporte y mantener sanos los pies y la piel antes, durante y después de la actividad física.

\section{¿Qué actividades físicas debo hacer si tengo diabetes?}




\section{Factores de riesgo que inciden en la presencia de diabetes}

Vol. 2, núm. 4., (2018)

Andrea Carolina Mariño Jara; Mary Isabel Vinces Zambrano; Andrea Natacha Pico Tagle; Andrés Patricio Morales Tipán; Olmedo Xavier Ruiz Lara; Cristian Manuel Chango Checa

Casi todos los tipos de actividad física pueden ayudarle en el manejo de su diabetes. Algunos pueden resultar peligrosos para ciertas personas, como para las que tienen visión deficiente o lesiones en los nervios de los pies. Pregúntele a su equipo de atención médica cuáles actividades físicas no suponen peligro para usted. Muchas personas prefieren caminar con sus amigos o parientes como forma de hacer ejercicio.

Hacer diferentes tipos de actividad física cada semana le brindará los mayores beneficios para la salud. Mezclarlas también ayuda a combatir el aburrimiento y disminuir su probabilidad de lesionarse. Pruebe algunas de las opciones de actividad física que le damos a continuación.

\section{Agregue actividad adicional a su rutina diaria}

Si usted ha tenido un periodo de inactividad o está iniciando una actividad nueva, comience lentamente, haciendo solo 5 a 10 minutos al día. Poco a poco vaya aumentando el tiempo cada semana. Puede aumentar su actividad diaria pasando menos tiempo delante del televisor u otra pantalla. Pruebe estas formas sencillas de añadir actividad física a su vida cada día:

- $\quad$ camine por la casa mientras habla por teléfono o durante las propagandas en la televisión

- haga tareas domésticas como trabajar en el jardín, rastrillar las hojas, limpiar la casa o lavar el automóvil

- $\quad$ deje su automóvil lo más lejos posible en el estacionamiento del centro comercial y camine hasta la tienda 


\section{Factores de riesgo que inciden en la presencia de diabetes}

Vol. 2, núm. 4., (2018)

Andrea Carolina Mariño Jara; Mary Isabel Vinces Zambrano; Andrea Natacha Pico Tagle; Andrés Patricio Morales Tipán; Olmedo Xavier Ruiz Lara; Cristian Manuel Chango Checa

- $\quad$ use las escaleras en lugar del ascensor

- $\quad$ haga que sus salidas familiares incluyan actividad física, como un paseo familiar en bicicleta o una caminata por el parque.

Si permanece sentado mucho tiempo trabajando en su escritorio o viendo televisión, haga alguna actividad ligera durante 3 o más minutos cada media hora. ${ }^{10}$ Las actividades ligeras incluyen:

- levantar o extender las piernas

- $\quad$ estirar los brazos por encima de la cabeza

- $\quad$ girar en la silla del escritorio

- $\quad$ hacer giros del torso

- $\quad$ hacer inclinaciones laterales

- $\quad$ caminar en el lugar (sin moverse del mismo sitio)

\section{Haga ejercicio aeróbico}

El ejercicio aeróbico es una actividad que hace que el corazón lata más rápido y que le sea más difícil respirar. La meta es hacer ejercicio aeróbico durante 30 minutos al día, la mayoría de los días de la semana. No tiene que hacer toda la actividad al mismo tiempo. Puede dividir estos minutos en unos cuantos periodos a lo largo del día. 
Factores de riesgo que inciden en la presencia de diabetes

Vol. 2, núm. 4., (2018)

Andrea Carolina Mariño Jara; Mary Isabel Vinces Zambrano; Andrea Natacha Pico Tagle; Andrés Patricio Morales Tipán; Olmedo Xavier Ruiz Lara; Cristian Manuel Chango Checa

Para sacar el máximo provecho de su actividad, el ejercicio debe ser de moderado a vigoroso. Intente:

- caminar a paso firme o hacer senderismo

- $\quad$ subir escaleras

- nadar o tomar clase de aeróbicos en el agua

- bailar

- $\quad$ montar en bicicleta (puede ser estacionaria)

- tomar clases de aeróbicos

- jugar baloncesto, tenis u otros deportes

Hable con su equipo de atención médica sobre cómo hacer ejercicios de calentamiento antes y enfriamiento después de hacer alguna actividad física.

\section{Haga entrenamiento de fuerza para aumentar la masa muscular}

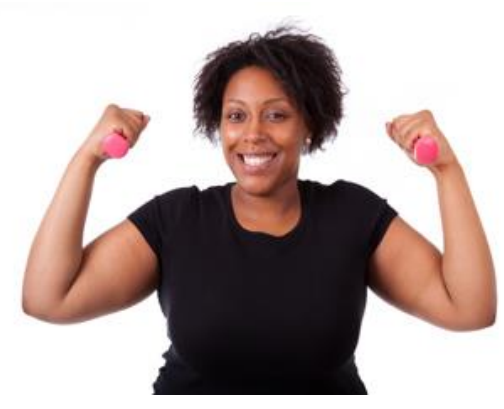




\section{Factores de riesgo que inciden en la presencia de diabetes}

Vol. 2, núm. 4., (2018)

Andrea Carolina Mariño Jara; Mary Isabel Vinces Zambrano; Andrea Natacha Pico Tagle;

Andrés Patricio Morales Tipán; Olmedo Xavier Ruiz Lara; Cristian Manuel Chango Checa

Usted puede hacer entrenamiento de fuerza con pesas de mano, bandas elásticas o máquinas de pesas.

El entrenamiento de fuerza es una actividad física leve o moderada que fortalece los músculos y ayuda a mantener los huesos sanos. El entrenamiento de fuerza es importante tanto para los hombres como para las mujeres. Cuando usted tiene más músculo y menos grasa corporal, quema más calorías y esto puede ayudarle a perder peso y no volver a subirlo.

Puede hacer entrenamiento de fuerza con pesas de mano, bandas elásticas o máquinas de pesas. Intente hacerlo dos a tres veces a la semana. Comience con poco peso y vaya aumentando poco a poco el tamaño de las pesas a medida que sus músculos se vuelven más fuertes.

\section{Haga ejercicios de estiramiento}

Los ejercicios de estiramiento son una actividad física leve o moderada. Los estiramientos aumentan la flexibilidad, disminuyen el estrés y ayudan a prevenir el dolor muscular.

Puede elegir entre muchos tipos de ejercicios de estiramiento. El yoga es un tipo de estiramiento que se centra en la respiración y ayuda con la relajación. Incluso si usted tiene problemas para moverse o de equilibrio, ciertos tipos de yoga pueden ser útiles. Por ejemplo, el yoga de silla tiene estiramientos que se pueden hacer sentado en una silla o apoyándose de una silla mientras está de pie. Su equipo de atención médica puede decirle si el yoga es adecuado para usted

\section{Conclusiones}




\section{Factores de riesgo que inciden en la presencia de diabetes}

Vol. 2, núm. 4., (2018)

Andrea Carolina Mariño Jara; Mary Isabel Vinces Zambrano; Andrea Natacha Pico Tagle; Andrés Patricio Morales Tipán; Olmedo Xavier Ruiz Lara; Cristian Manuel Chango Checa

La prevención de la diabetes es algo tan básico como comer de forma más saludable, hacer más actividad física y bajar algunos kilos. Nunca es tarde para empezar. Hacer algunos cambios en tu estilo de vida ahora podría ayudarte a evitar complicaciones graves de la salud debido a la diabetes con el paso del tiempo, como daños a los nervios, en los riñones y en el corazón.

Las investigaciones indican que los ejercicios aeróbicos y el entrenamiento de resistencia pueden ayudar a controlar la diabetes. El mayor beneficio puede lograrse con un programa de ejercicios que combine ambos tipos de entrenamiento.

Entre las medidas para prevenir la hipoglucemia cabe citar la realización de un mayor número de controles de glucemia durante el día, sobre todo si se ha hecho ejercicio físico, así como la planificación con antelación del ejercicio físico que se va a realizar para poder ajustar la insulina que se va a administrar y los hidratos de carbono que se van a comer.

En consecuencia, a través de cualquiera de los dos mecanismos, la glucosa se acumula en la sangre y los órganos se quedan sin combustible para su funcionamiento. El aumento del azúcar en sangre por encima de valores normales se denomina hiperglucemia. La hiperglucemia sostenida y sin tratamiento puede dar lugar a complicaciones en diferentes órganos, como los ojos, riñones, corazón, arterias y pies, entre otras.

\section{Bibliografía.}

1. MedlinePlus. Diabetes. Rockville: Biblioteca Nacional de Medicina de los EE. UU.; 2018.

2. MedlinePlus. Diabetes tipo 2. Rockville: Biblioteca Nacional de Medicina de los EE. UU.; 


\section{Factores de riesgo que inciden en la presencia de diabetes}

Vol. 2, núm. 4., (2018)

Andrea Carolina Mariño Jara; Mary Isabel Vinces Zambrano; Andrea Natacha Pico Tagle;

Andrés Patricio Morales Tipán; Olmedo Xavier Ruiz Lara; Cristian Manuel Chango Checa

2018.

3. NIH. ¿Qué es la diabetes?. Bethesda: National Institutes of Health; 2017.

4. Conesa González AI, González Calero TM. Aspectos más recientes en relación con la diabetes mellitus tipo MODY. Revista Cubana de Endocrinología. 2012; 23(2): p. 186-194.

5. Medina-Pérez E, Sánchez-Reyes A, Hernández-Peredo A, Martínez-López M. Diabetes gestacional. Diagnóstico y tratamiento en el primer nivel de atención. Medicina interna de México. 2017 Feb; 33(1): p. 91-98.

6. Siqueira Péres D, dos Santos MA, Zanetti ML. DIFICULTADES DE LOS PACIENTES DIABÉTICOS PARA EL CONTROL DE LA ENFERMEDAD: SENTIMIENTOS Y COMPORTAMIENTOS. Rev Latino-am Enfermagem. 2007 Dic; 15(6): p. 1-8.

7. Fernández Regalado R, Arranz Calzado MC, Ortega Sam JÁ. Resistencia a la insulina y cambios metabólicos en adultos obesos. Revista Cubana de Endocrinología. 2011 Ago; 22(1): p. 78-90.

8. Llorente Columbié Y, Miguel-Soca PE. Factores de riesgo asociados con la aparición de diabetes mellitus tipo 2 en personas adultas. Revista Cubana de Endocrinología. 2016 Ago; 27(2): p. 123-133.

9. Pereira Despaigne OL, Palay Despaigne MS, Rodríguez Cascaret A. Hemoglobina glucosilada en pacientes con diabetes mellitus. MEDISAN. 2015 Abr; 19(4): p. 555-561. 